\title{
Recent Advances in the use of Ionic Liquids for Electrochemical
}

\author{
Sensing \\ Debbie S. Silvester* \\ Nanochemistry Research Institute, Department of Chemistry, Curtin University, GPO Box U1987, Perth,
6845, Australia.
*E-mail: d.silvester-dean@curtin.edu.au; Fax:+61(8)92664699; Tel:+61(8)92667148
}

Submitted to The Analyst (as an invited Mini Review)

\begin{abstract}
Ionic Liquids are salts that are liquid at (or just above) room temperature. They possess several advantageous properties (e.g. high intrinsic conductivity, wide electrochemical windows, low volatility, high thermal stability and good solvating ability), which make them ideal as non-volatile electrolytes in electrochemical sensors. This mini-review article describes the recent uses of ionic liquids in electrochemical sensing applications (covering the last 3 years) in the context of voltammetric sensing at solid/liquid, liquid/liquid interfaces and carbon paste electrodes, as well as their use in gas sensing, ion-selective electrodes, and for detecting biological molecules, explosives and chemical warfare agents. A comment on the future direction and challenges in this field is also presented.
\end{abstract}

\section{Keywords}

Room Temperature Ionic Liquids, Sensing, Electrochemical Sensors, Voltammetry, Gas Sensing, Biological molecules, Explosives 


\section{Introduction}

Room Temperature Ionic Liquids (RTILs) are an exciting class of solvent, receiving much attention in recent years as a replacement for conventional solvents in a wide range of applications. Ionic liquids (ILs) are defined as salts that melt below $100{ }^{\circ} \mathrm{C}^{1}$ and room temperature ionic liquids (RTILs), as their name suggests, exist in the liquid state at room temperature $\left(25^{\circ} \mathrm{C}\right)$. They are typically comprised of a bulky organic cation (e.g. imidazolium, tetraalkylammonium or pyrrolidinium) paired with an inorganic/organic anion (e.g. tetrafluoroborate, hexafluorophosphate, bis(triflurormethylsulfonyl)imide). The structures of some commonly used cations and anions are shown in Figure 1, along with the nomenclature used throughout this article. ${ }^{\S}$ RTILs possess several archetypal properties such as low-volatility, high physical and chemical stability, wide electrochemical windows, intrinsic conductivity, wide liquid range, high polarity and the ability to dissolve a wide range of compounds. ${ }^{1,2}$ In addition to the use of RTILs in applications such as catalysis, $^{1-3}$ 'green' chemistry, ${ }^{4,5}$ organic reactivity, ${ }^{6,7}$ analytical methods, ${ }^{8,} 9$ biocatalysis and enzymes $^{10,11}$ and applications in the chemical industry, ${ }^{12}$ they have also become recognised as ideal alternative electrolytes for use in many electrochemical devices, such as actuators, ${ }^{13}$ capacitors, ${ }^{14-16}$ batteries, ${ }^{17}$ fuel cells, ${ }^{18}$ solar cells ${ }^{19}$ and sensors. ${ }^{20}$ It is the latter application that is the focus of this review.

There are three main types of electrochemical sensors based on either the measurement of a redox current (amperometric), the development of a potential (potentiometric) or a change in resistance (conductometric). Amperometric sensors typically consist of two or three electrodes connected through an electrolyte medium. The analyte species diffuses through the electrolyte to be detected at the working electrode surface. Potentiometric sensors (e.g. ion selective electrodes) usually consist of a membrane that contains ion exchangers, lipophilic salts and plasticizers, and the trans-membrane potential gives the activity of the analyte ion in solution. RTILs have the ability to replace conventional electrolyte systems in amperometric/potentiometric sensors and this is

\footnotetext{
$\S$ It is noted here that a general recommendation for the nomenclature of ionic liquids does not currently exist, but the naming conventions adopted correspond to those most commonly used in the articles referenced in this review.
} 
becoming the topic of many laboratory investigations, although this research is still in the early stage and RTIL based sensors are yet to be commercialized. Before the widespread use of RTILbased sensors can occur, the electrochemical behaviour of analytes in RTILs, together with sensitivity (detection limits) and selectivity in RTILs, needs to be fully understood. The focus of this review is to describe some recent developments using RTILs in electrochemical sensing applications. For the background and properties of electrochemistry in RTILs, interested readers are directed to several excellent review papers that cover these topics in detail. ${ }^{21-24}$ This review paper follows on from two reviews (by Wei and Ivaska ${ }^{25}$ and Shvedene et al. ${ }^{26}$ ) that were published around the same time in 2008 and a biosensor-focussed review (by Shiddiky and Torriero ${ }^{27}$ ) published in early 2011. This overview will therefore describe only recent works in the last 3 years (excluding biosensors, here taken to be sensors that incorporate a biological recognition process), from mid 2008-mid 2011. The focus will be first on voltammetric sensing at solid|IL and liquid|IL interfaces, and at carbon paste electrodes, followed by the use of RTILs in gas sensors, ion-selective electrodes (ISEs) and for the detection of biological molecules, explosives and chemical warfare agents. This will show that ionic liquids have many advantageous properties that can be exploited in sensor devices for selective analyte detection.

\section{Applications of Ionic Liquids in Electrochemical Sensing}

\subsection{Voltammetric Sensing}

Voltammetry is a powerful suite of tools used by electrochemists to monitor concentrations and diffusion coefficients of species in solution and to understand their behaviour and electrochemical reaction mechanisms. The technique can be applied to any species than can undergo redox transitions on solid electrodes, or any ion that can be transferred across interfaces (in the case of liquid/liquid experiments). Voltammetry typically takes place with two- or three- electrodes that are connected through an electrolyte medium (e.g. water or organic solvents containing a background electrolyte). RTILs have been investigated as an alternative electrolyte medium over the past 10 years or so and have been shown to be very favourable media due to their intrinsic conductivity, 
wide electrochemical windows, low volatility and their ability to solvate a wide range of compounds. ${ }^{28}$ Although there has been a lot of work focussed on understanding reaction mechanisms and kinetics and thermodynamics of electrochemical reactions in RTILs, ${ }^{21,28}$ the focus here will be only on the works that suggest the use of RTILs in electrochemical sensing applications. This topic will be split into three sections: sensing at solid/RTIL interfaces, sensing at liquid/RTIL interfaces and sensing using RTILs as a binder (e.g. in carbon paste electrodes). It is clear that RTILs have huge potential for use in robust voltammetric sensors.

\subsubsection{Sensing at Solid/liquid interfaces}

The electrochemical behaviour of various species at solid electrodes in ionic liquids is a very active area, with most studies focussing on understanding the reaction mechanisms and comparing behaviour to that in conventional electrolyte systems. On the whole, reactions and mechanisms have been found to be the same in ionic liquids and conventional solvents, however, some notable differences and anomalous behaviour have been observed in RTILs, which are highlighted in a comprehensive review article. ${ }^{21}$ It is extremely important to understand any anomalous behaviour in RTILs before they can be employed as direct replacements for conventional molecular solvents (containing supporting electrolytes) in sensor devices. In the last few years, several authors have recognized the advantageous properties of RTILs as electrolytes for sensors. A few key recent advances in the area of voltammetric sensing at solid electrodes are highlighted below. The sensing of biological molecules, gases and explosive/chemical warfare agents at solid electrodes will be described in later sections of this review.

One example of the use of RTILs for voltammetric sensing is reported by Lu et al. ${ }^{29}$ who used a task specific ionic liquid (TSIL, i.e. an RTIL that has a specific functional group) in combination with bismuth oxide $\left(\mathrm{Bi}_{2} \mathrm{O}_{3}\right)$ for the electrochemical detection of heavy metal oxides including cadmium oxide $(\mathrm{CdO})$, copper oxide $(\mathrm{CuO})$ and lead oxide $(\mathrm{PbO})$ (see Figure 2). The TSIL contained a $\left[\mathrm{NTf}_{2}\right]^{-}$anion and a tetraalkylammonium cation with one carbon chain functionalised with a carboxylic acid group. The presence of the acid group allowed for 
solubilisation of the metal oxides into the ionic liquid. The TSIL was coated as a thin layer onto a surface containing three indium tin oxide (ITO) printed electrodes (working, counter and reference electrode) and acted as the selective solubilisation medium and electrolyte. After a 120 sec accumulation time at $-1.1 \mathrm{~V}$ (where the metal oxides were deposited) $\mathrm{CdO}$, $\mathrm{CuO}$ and $\mathrm{PbO}$, exhibited well-defined stripping voltammetry with peak currents that were linearly proportional to concentration over the range 1 to $8 \mathrm{ng} / \mathrm{L}$ and low detection limits of ca. $0.28,0.30$ and $0.34 \mathrm{ng} / \mathrm{L}$ for $\mathrm{CdO}, \mathrm{CuO}$ and $\mathrm{PbO}$, respectively. It was observed that the same experiments employing RTILs without task-specific functional groups (such as $\left[\mathrm{C}_{4} \mathrm{mim}\right]\left[\mathrm{PF}_{6}\right]$ ) did not show any stripping signals, suggesting that many more species may be able to be detected by selective "tuning" of the RTIL structure (e.g. to improve solubility). It is envisioned that more analyte species may begin to be detected by employing newly-synthesized TSILs with specific functional groups.

Huang et al. ${ }^{30}$ used a nanoporous gold electrode coated with a self assembled monolayer of 3-mercaptopropylsulfonate (MPS) to detect the concentration of copper metal $\left(\mathrm{Cu}^{2+}\right)$ in water using stripping voltammetry. The working electrode was formed by electrodeposition of zinc on gold to form $\mathrm{Au}_{\mathrm{x}} \mathrm{Zn}_{1-\mathrm{x}}$ in a 40-60 mol\% zinc chloride-[C $\left.\mathrm{C}_{2} \mathrm{mim}\right] \mathrm{Cl}$ ionic liquid, followed by removal of $\mathrm{Zn}$ to give nanostructured gold and self assembled monolayer formation of MPS. The prepared electrode was used in conjunction with a $\mathrm{Ag} / \mathrm{AgCl}$ reference electrode and a gold wire counter electrode and placed in aqueous solutions of $0.1 \mathrm{M} \mathrm{NaNO}_{3}$ containing $\mathrm{Cu}^{2+}$. The calibration curve showed linear behaviour (current vs. concentration) over the range 0.1 to $5 \mu \mathrm{g} / \mathrm{L} \mathrm{Cu}^{2+}$ with a low detection limit of $2 \mathrm{ng} / \mathrm{L}$ (or $0.031 \mathrm{nM}$ ). Although the RTIL was not directly used in the sensing process, it provided a solvent medium that can withstand the high temperatures $\left(\sim 120{ }^{\circ} \mathrm{C}\right)$ that are required for the alloy formation; this cannot be achieved with conventional volatile solvents. This presents an alternative mercury-free method to detect $\mathrm{Cu}^{2+}$ and has the potential to be applied wide variety of metals of interest.

\subsubsection{Sensing at liquid/liquid interfaces}


Electrochemistry at the Interface between Two Immiscible Electrolyte Solutions (ITIES) is a powerful method to detect ions that are not redox-active at conventional solid|liquid interfaces. It relies on the transfer of ions across the interface, as opposed to electron exchange at solid electrodes. ITIES experiments typically take place at water|organic solvent interfaces, with solvents such as 1,2-dichloromethane, 1,6-dichlorohexane and nitrobenzene commonly employed. ${ }^{31}$ In recent years, ionic liquids have also been explored as an alternative water-immiscible solvent phase. The reader is directed to an excellent review article by Samec and Kakiuchi ${ }^{32}$ describing their $^{2}$ pioneering and recent work in this area. Readers are also referred to an in-depth review paper by Opallo and Lesniewski ${ }^{33}$ that describes some applications of sensing at electrodes modified with ionic liquid droplets, with reactions occurring at the three-phase boundary (solid|RTIL|aqueous). There are many potential applications for sensing at the liquid/liquid interface, however, here some of the recent reports of the detection of ions transferring across liquid/liquid interfaces (as opposed to droplet modified electrodes) are highlighted. The main advantage of this type of sensing compared to solid/liquid sensing is that the RTIL is usually pre-saturated with water, so any differences in humidity in the environment will not affect the overall sensor response. The group of Kakiuchi has been quite active in this research area, following their pioneering work in $2003 .{ }^{34}$ In collaboration with Mirkin, they recently reported kinetics of ion transfer at the ionic liquid/water nanointerface. ${ }^{35}$ The interface was formed at the tip of a nanopipette (with radii from 10 to $150 \mathrm{~nm}$ ) and the transfer of tetrabutylammonium from water to the hydrophobic RTIL $\left[\mathrm{P}_{14,6,6,6}\right]\left[\mathrm{C}_{4} \mathrm{C}_{4} \mathrm{~N}\right]$ (structure shown in Figure 1) was reported. Although the authors did not specifically describe the application of their work in sensing, this could have implications in the field due to the use of very small (nano) interfaces that gives rise to lower ohmic drop (important in resistive media such as ionic liquids) and higher current density, which is highly beneficial for sensing applications. Perhaps most importantly, the same group have also highlighted the ultra-slow relaxation of the electrical double layer in RTILs at millimeter $^{36}$ (but not nanometer) ${ }^{35}$ sized interfaces, which may lead to self-inhibition of the charge transfer step across the RTIL-water boundary, limiting the performance of a sensor that relates charge transfer to analyte concentration. More research is 
required in this area to understand the impact of the ultraslow relaxation on sensor responses and behaviour.

Other researchers have also contributed to this area. For example, Ballantyne et al. ${ }^{37}$ reported the formation of stable liquid/liquid interfaces between water and a range of hydrophobic ionic liquids. The interface was formed within a hole of $10 \mu \mathrm{m}$ diameter, and a 4-electrode system was employed. They showed cyclic voltammetry for the transfer of tetramethylammonium from water to the RTIL $\left[\mathrm{N}_{10,6,6,6}\right]\left[\right.$ TPBF20]. Very recently, Silvester and Arrigan ${ }^{38}$ reported the transfer of several common ions (three cations and three anions) across the interface between water and a commercially available hydrophobic RTIL $\left[\mathrm{P}_{14,6,6,6}\right][\mathrm{FAP}]$ with a melting point of $<-50{ }^{\circ} \mathrm{C}$ (i.e. a liquid well below RT). This was the first report of voltammetry at an array of water|RTIL microinterfaces, rather than at a single interface or porous polymer supported-interface. The interface array was formed within the micropores of a silicon chip membrane (30 pores and $23 \mu \mathrm{m}$ diameter) and provided advantages of micron-sized interfaces (radial diffusion, higher current densities and lower iR drop) but with larger currents for sensing low concentrations of redoxinactive ions. This work has shown that sensing of various ions is possible at the water-RTIL interface, but it was limited to ions that transfer at potentials less negative that the RTIL anion (e.g. $\mathrm{FFP}^{-}$) transfers to water. As a result, the synthesis of RTILs with (even more) extremely hydrophobic cations and anions (which are not yet available at present in the liquid form) is required in order to extend the potential windows to those similar to organic solvent/supporting electrolyte systems (e.g. $0.9 \mathrm{~V}$ ). If this is possible, this should allow for the observation of species that have been detected at the positive potential limit in water/organic solvent systems e.g. important biomolecules such as lysozyme and haemoglobin. ${ }^{39}$

\subsubsection{Sensing at electrodes using ionic liquids as a binder}

Recently, ionic liquids have been found to be efficient binders in the preparation of carbon composite/carbon paste electrodes (CPEs). They are prepared by mixing or grinding graphite particles with the ionic liquid, followed by the transfer of this mixture into a cavity of a polymer or 
glass tube. By substituting a non-conductive organic binder (e.g. oil) with ionic liquids, low cost and easy to fabricate electrodes have been produced, with the advantages of high conductivity and improved electrochemical performances compared to traditional oil-based electrodes. Figure 3 shows a sketch of the electrode reaction mechanisms at oil-based CPEs compared to ionic liquid carbon paste electrodes (ILCPEs). ${ }^{33}$ Higher currents (both faradaic and capacitive) are often observed at ILCPEs compared to traditional CPEs, This is believed to be due to the larger electroactive area for electron transfer in the ILCPEs (represented as curved arrows on Figure 3) due to the conductive RTIL medium. In traditional oil-based CPEs, electron transfer can only take place at the carbon/aqueous electrolyte interface. Other reasons for the higher currents may also be: changes in paste morphology, better solubility of polar analytes in the RTIL (compared to the binder) or the presence of additional interface where transfer across the liquid/liquid interface can occur (straight arrows on Figure 3). This section will discuss the recent use of ionic liquids as a binder for voltammetric sensing applications. Other uses of carbon paste electrodes for the detection of biological molecules are discussed in section 2.4 .

Kim et al. ${ }^{40}$ reported the fabrication of a multi-walled carbon nanotube (MWCNT) ionic liquid electrode for the voltammetric detection of phenolic compounds in red wine. The MWCNT ionic liquid was prepared by the immobilisation of 1-butylimidazole bromide onto an epoxy group on a poly(glycidyl methacrylate)-grafted MWCNT. The working electrode was fabricated by dropcasting the MWCNT ionic liquid solution (with tyrosinase and chitosan) on an indium tin oxide (ITO) glass. A three-electrode system with a $\mathrm{Ag} / \mathrm{AgCl}$ (satd. $\mathrm{KCl}$ ) reference electrode and a Pt wire counter electrode was employed. Three brands of red wine were tested in a background of phosphate buffer solution. The sensing range for phenolic compounds was 0.01 to $0.08 \mathrm{mM}$ and the concentration of phenolics in commercial red wines was determined to be in the range of ca. 400$3000 \mathrm{mg} / \mathrm{L}$.

Sun et al. ${ }^{41}$ employed an ionic liquid $\left(\left[\mathrm{C}_{4} \mathrm{mim}\right]\left[\mathrm{PF}_{6}\right]\right)$-based carbon (graphite) ionogel electrode for the voltammetric detection of hydroquinone. The fabricated electrode was employed in a 3-electrode setup with a saturated calomel reference electrode and a platinum wire counter 
electrode. Hydroquinone solutions were prepared in aqueous phosphate buffer solutions as the supporting electrolyte and differential pulse voltammetry was performed on different concentrations of hydroquinone. A good linear relationship was observed between current and concentration in the range 0.13 to $100 \mu \mathrm{M}$ with a detection limit of $70 \mathrm{nM}$.

Xu et al. ${ }^{42}$ used a glassy carbon (GC) electrode modified with two conducting components: acetylene black (AB) and the RTIL $\left[\mathrm{C}_{4} \mathrm{mim}\right]\left[\mathrm{PF}_{6}\right]$, for the detection of trifluralin (a herbicide) in soil samples. The modified working electrode was used in a 3-electrode set-up with a saturated calomel reference electrode and a platinum wire counter electrode, in a background of $\mathrm{pH} 5.5$ phosphate buffer solution as a supporting electrolyte. Here, the analyte (triflualin) partitions from water into the AB-RTIL film and is detected by cyclic voltammetry at the GC electrode. A linear response between current and concentration was obtained in the range from 0.08 to $12 \mu \mathrm{M}$ trifluralin, with a low detection limit of $10 \mathrm{nM}$ after an accumulation step of 120 seconds at open circuit potential. Using an ionic liquid as the binder provided improved conductivity and higher sensitivity compared to similar modified electrodes without ionic liquids.

These three reports suggest that RTILs can be easily employed as a binder in carboncomposite electrodes, with good responses for analyte detection in synthetic and real-world samples. In particular, the higher currents at IL-CPEs compared to oil-CPEs has huge advantages for sensing applications. The ease of preparation and the low-cost of such sensing systems suggest that this could be a very active field for future sensing of species in the food/drink industry and for environmental monitoring of soil/water samples and more work in this area is expected.

\subsection{Gas Sensing}

RTILs have recently shown much promise as stable and non-volatile electrolytes in amperometric gas sensors. A typical amperometric gas sensor consists of three electrodes connected through an electrolyte, which is covered by a gas-permeable membrane. The gas passes through the membrane, diffuses through the electrolyte and is detected at the working electrode. Most commercially available amperometric sensors of gases (e.g. $\mathrm{O}_{2}, \mathrm{CO}, \mathrm{SO}_{2}, \mathrm{H}_{2} \mathrm{~S}, \mathrm{NO}_{2}, \mathrm{Cl}_{2}$ ) currently employ 
conventional solvents (e.g. $\mathrm{H}_{2} \mathrm{SO}_{4} / \mathrm{H}_{2} \mathrm{O}$ mixtures, or organic solvents such as acetonitrile or propylene carbonate) that cannot survive drastic temperature changes or extremely dry or humid conditions. The "lifetime" of a sensor is often determined by how quickly the electrolyte dries up and the solvent often has to be replaced every few days/weeks in the most extreme conditions. RTILs possess negligible volatility and high chemical stability, making them ideal electrolyte media in robust gas sensors for potential application in more extreme operating conditions (e.g. up to 300 ${ }^{\circ} \mathrm{C}$ ), with no possibility of solvent evaporation or degradation. This, combined with the intrinsic conductivity (no need for supporting electrolyte), wide potential windows (to investigate compounds that may have been inaccessible otherwise) and in some cases, increased gas solubility in RTILs, makes them ideal electrolyte media for gas detection. Recent advances in amperometric gas sensing using RTIL solvents is thoroughly reviewed by Rogers et al. ${ }^{43}$ who describe the electrochemistry of various gases including oxygen, carbon dioxide, hydrogen, ammonia, hydrogen sulfide, sulfur dioxide and nitrogen dioxide in RTILs. The same group also suggested the possibility to use RTILs in membrane-free amperometric gas sensors, as depicted in Figure $4 .^{20}$ The elimination of a membrane may allow for improved response time, since the analyte gas is in direct contact with the electrolyte and has only a single medium to diffuse through before detection at the working electrode surface. Some of the most recent advances using RTILs for gas sensing (amperometric and otherwise) are reviewed below. It is expected that more work will take place in this important area, particularly towards commercialization of highly robust amperometric gas sensors for use in extreme (high temperature and pressure) environments.

Elegant work was carried out by Compton and co-workers, ${ }^{44}$ who proposed a membranefree Clark-type $\mathrm{O}_{2}$ sensor, consisting of a microelectrode array of $8012 \mu \mathrm{m}$ diameter gold recessed microelectrodes fabricated on a silicon chip. The RTIL used was the hydrophobic ionic liquid $\left[\mathrm{P}_{14,6,6,6}\right][\mathrm{FAP}]$ which was found to readily form thin films $(0.2 \mu \mathrm{L}$ corresponding to ca. $6 \mu \mathrm{m}$ thickness) on the hydrophobic surface of the microarray. A fast response to $\mathrm{O}_{2}$ (ca. 20 seconds from introduction of the gas) was observed over a concentration range of 2-13 v/v \%. The use of small (micron-sized) working electrodes minimises any iR/Ohmic drop limitations that are often 
associated with voltammetry in highly resistive RTILs on larger electrodes (larger currents). The same group also reported the electrochemical reaction mechanisms of carbon dioxide, hydrogen sulfide and chlorine gas in ionic liquids. For example, the electrochemical reduction of $\mathrm{CO}_{2}$ in the RTIL $\left[\mathrm{C}_{4} \mathrm{mim}\right][\mathrm{Ac}]$ was studied on a Pt microelectrode using cyclic voltammetry. ${ }^{45} \mathrm{CO}_{2}$ undergoes a chemically irreversible one-electron reduction to the radical anion $\mathrm{CO}_{2}{ }^{--}$and subsequent follow-up chemistry including interaction/complexation with the ionic liquid. The behaviour was found to be irreversible due to strong absorption of $\mathrm{CO}_{2}$ in the RTIL, suggesting that this system may not be suitable for real-time sensing of $\mathrm{CO}_{2}$, however, the high solubility $(>1.5 \mathrm{M})$ of $\mathrm{CO}_{2}$ in $\left[\mathrm{C}_{4} \mathrm{mim}\right][\mathrm{Ac}]$ suggests a method for sequestration of the greenhouse gas. The mediated detection of hydrogen sulfide on a Pt microelectrode was reported in the RTIL $\left[\mathrm{C}_{2} \mathrm{mim}\right]\left[\mathrm{NTf}_{2}\right]{ }^{46}$ It was observed that the presence of 2,3-tert-butyl-o-benzoquinone in the RTIL resulted in a decreased potential for the analyte signal, due to the reaction of the mediator with $\mathrm{H}_{2} \mathrm{~S}$. Concentrations in the range 200-10,000 ppm $\mathrm{H}_{2} \mathrm{~S}$ were studied, with reversible behaviour observed over short times (0-20 mins). However, the response times were long (140 minutes) but as the authors note, the response times quoted reflect the relatively large volume of electrolyte: faster response times are expected with an improved sensor design. Compton's group also reported the two-electron reduction of $100 \%$ chlorine gas to chloride on a Pt microelectrode in a range of ionic liquids $\left(\left[\mathrm{C}_{2} \mathrm{mim}\right]\left[\mathrm{NTf}_{2}\right]\right.$, $\left[\mathrm{C}_{4} \mathrm{mim}\right]\left[\mathrm{NTf}_{2}\right],\left[\mathrm{C}_{4} \mathrm{mpyrr}\right]\left[\mathrm{NTf}_{2}\right], \quad\left[\mathrm{C}_{4} \mathrm{mim}\right]\left[\mathrm{BF}_{4}\right],\left[\mathrm{C}_{4} \mathrm{mim}\right]\left[\mathrm{PF}_{6}\right],\left[\mathrm{C}_{4} \mathrm{mim}\right][\mathrm{OTf}],\left[\mathrm{N}_{6,2,2,2}\right]\left[\mathrm{NTf}_{2}\right]$ and $\left.\left[\mathrm{C}_{6} \mathrm{mim}\right] \mathrm{Cl}\right) .{ }^{47}$ The behaviour of the voltammetry at various scan rates was highly unusual, with limiting currents observed to decrease with increasing sweep rate. This intriguing observation was assigned to a mechanism of adsorption of chlorine gas on the Pt electrode surface. The adsorbed chlorine itself cannot be reduced, but must undergo desorption before the electron transfer step. At slower scan rates (longer timescales), there is more desorption resulting in more of the surface available for electron-transfer; this gives rise to higher currents at slower scan rates. The large voltammetric currents observed suggest that $\mathrm{Cl}_{2}$ has a very high solubility (1-10 M) in RTILs, making these solvents attractive for the purposes of $\mathrm{Cl}_{2}$ gas sensors. ${ }^{47}$ The authors did not report the effect of varying concentrations of $\mathrm{Cl}_{2}$ on the current response, but this seems like the next logical 
step especially given the unusual adsorption mechanism. If the current scales linearly with concentration, RTILs may prove to be a useful medium for robust $\mathrm{Cl}_{2}$ gas sensing.

Other authors have also employed RTILs for amperometric gas sensing. For example, an elegant free standing Pt-Au bimetallic membrane with a leaf-like nanostructure was proposed by Shen et al. ${ }^{48}$ for the amperometric detection of oxygen in four different ionic liquids containing the [NTf $\left._{2}\right]^{-}$anion. A small volume $(1 \mu \mathrm{L})$ of ionic liquid was used to create a layer (thickness $\left.40 \mu \mathrm{m}\right)$ that was connected to the bimetallic working electrode surface and silver wire quasi reference/counter electrode. A linear relationship (current vs. concentration) was observed for oxygen in the range 0.05 to $0.4 \mathrm{vol} \% \mathrm{O}_{2}$, with a fast response time (steady state signals were observed within several seconds), high current density and very small background currents (comparable to those at solid microelectrode|RTIL interfaces). $\mathrm{Ng}$ et al. $^{49}$ employed a nanocomposite gel consisting of a three-dimensional graphene material and the ionic liquid $\left[\mathrm{C}_{4} \mathrm{mim}\right]\left[\mathrm{PF}_{6}\right]$ for the amperometric detection of nitric oxide (NO). A linear response of current vs. concentration over the range 1-16 $\mu \mathrm{M}$ NO was observed, with a fast response time of less than 4 seconds and a low detection limit of $16 \mathrm{nM}$. The authors state that this is better than that of other NO sensing platforms based on carbon nanotubes and gold nanoparticles. The improved response is attributed to the porous graphene material that has a high specific surface area and superior conductivity. The 3-D graphene/IL nanocomposite can provide a novel platform for sensitive NO detection.

An ethylene gas sensor employing a thin layer of the RTIL $\left[\mathrm{C}_{4} \mathrm{mim}\right]\left[\mathrm{BF}_{4}\right]$ on a "lab-on-achip” sensor was proposed by Zevenbergen et al. ${ }^{50}$ The sensor consisted of a $1 \mathrm{~mm}$ diameter Au working electrode surrounded by a Pt ring-shaped quasi-reference electrode and a Pt rectangular counter electrode (see Figure 5). Cyclic voltammetry of ethylene in the RTIL revealed an oxidation peak before the onset of gold oxidation. Interestingly, the ethylene oxidation peak was only visible when water was present in the RTIL; no response was observed with humidity levels less than 20 $\%$. As a result, the authors studied the dependence on humidity and observed larger responses when the humidity level was higher. A detection limit of $760 \mathrm{ppb}$ and a linear response (current vs. 
concentration) up to $10 \mathrm{ppm}$ were achieved. This suggests that amperometric ethylene detection in RTILs is possible, however it is limited only to environments with sufficient humidity levels (more than $40 \%$ ), which limits the application of such a sensor in extremely dry environments.

These reports have shown that RTILs are highly favourable media for use in electrochemical gas sensors. In many cases, the RTIL is used directly in contact with a bare metal electrode (cf. Clark cell) or combined with other materials (e.g. bimetallic membranes, graphene, polyaniline) for improved responses. The low volatility of RTILs is a particular advantage since the use of a membrane can be eliminated. It appears as though the most logical step forward in this area is to employ thin RTIL layers to overcome the slow diffusion often associated with viscous RTILs. This may result in decreased response times, on the order of minutes or seconds, which is ideal for most gas sensor device requirements. Additionally, to improve current density and to overcome iR/Ohmic drop common in resistive RTILs, small sized working electrodes (e.g. micro- or microarray) and eventually “lab-ob-a-chip” type systems are predicted to become widely used.

\subsection{Ionic Liquids in ISEs}

Ion Selective Electrodes (ISEs) have been developed over the last four decades as sensitive and inexpensive sensors to measure analytes of environmental and medical importance, and typically have a fast reversible response to the analyte of interest. ISEs produce a potential (EMF) that is proportional to the trans-membrane difference in activity of ions. Conventional ISEs employ four components in the membrane: (1) a skeleton e.g. PVC, (2) a plasticizer e.g. 2-nitrophenyloctylether (NPOE) or dioctyl sebacate (DOS), (3) an ion exchanger e.g. $\mathrm{K}^{+} \mathrm{R}^{-}$(where $\mathrm{R}^{-}=$lipophilic anion) and (4) an ionophore e.g. valinomycin (selective to $\mathrm{K}^{+}$over $\mathrm{Na}^{+}$). Ionic liquids (ILs) have recently been employed as an alternative to plasticizers and ion exchangers in membranes of ISEs. It is noted that most of the ILs used for ISEs have melting points slightly above room temperature, so it is not appropriate to refer to them here as RTILs. Several authors have successfully incorporated ionic liquids for fundamental sensing of ions, as described below, suggesting the possibility to 
incorporate lipophilic ionic liquids into membranes of potentiometric and amperometric ionselective electrodes.

For example Nishi et al. ${ }^{51}$ used the hydrophobic RTIL $\left[\mathrm{N}_{8,8,8,1}\right]\left[\mathrm{C}_{4} \mathrm{C}_{4} \mathrm{~N}\right]$ containing the ionophore dicyclohexano-18-crown-6 (DCH18C6) for the potentiometric detection of $\mathrm{K}^{+}$in water. Facilitated ion transfer voltammetry was reported for $\mathrm{K}^{+}$(from water to the RTIL) and the twophase system was used for the potentiometric determination of $\mathrm{K}^{+}$. A Nernstian response to $\mathrm{K}^{+}$(59 $\mathrm{mV}$ per decade) was observed over the concentration range $10^{-5}$ to $10^{-1} \mathrm{M}$ with a response time of 20 minutes. Langmaier and Samec $^{52}$ employed a thin $(112 \mu \mathrm{m})$ microporous membrane impregnated with valinomycin and the hydrophobic ionic liquid $\left[\mathrm{N}_{12,12,12,1}\right][\mathrm{TFPB}]$ for the facilitated amperometric detection of $\mathrm{K}^{+}$and $\mathrm{Na}^{+}$. Cyclic voltammetry for $\mathrm{K}^{+}$and $\mathrm{Na}^{+}$transfer from water to the RTIL membrane was reported, and the use of the RTIL in the membrane provided enhanced stability and selectivity compared to conventional $\mathrm{K}^{+}$ISEs. The RTIL membrane electrode was used to detect $\mathrm{K}^{+}$and $\mathrm{Na}^{+}$in table and tap water samples (0.02 to $\left.3.4 \mathrm{mM}\right)$ in the presence of a large excess $(1 \mathrm{M})$ of interfering ions such as $\mathrm{Mg}^{2+}$ and $\mathrm{Ca}^{2+}$. The same group ${ }^{53}$ employed a similar $\mathrm{K}^{+}$ISE containing the same ionic liquid, but with the addition of a water-soluble crown ether (18-crown-6) to the aqueous phase. This made it possible to distinguish the voltammetric waves of various alkali metal cations $\left(\mathrm{K}^{+}, \mathrm{Na}^{+}, \mathrm{Li}^{+}\right.$and $\left.\mathrm{Mg}^{2+}\right)$ and the promising results suggest that the RTIL-membrane may be suitable for application in an amperometric ISE for $\mathrm{K}^{+}$

Chernyshov et al. ${ }^{54}$ used low-melting ionic solids (LMISs, defined as ILs that melt slightly above room temperature) for the potentiometric determination of salicylate, perchlorate, thiocyanate and iodide ions in water. Three LMISs $\left[\mathrm{N}_{6,6,6,6}\right][\mathrm{BSB}],\left[\mathrm{N}_{8,8,8,8}\right][\mathrm{BSB}]$ and $\left[\mathrm{N}_{8,8,8,1}\right][\mathrm{BSB}]$ were examined as suitable salts for both liquid-contact and solid-contact ISE membranes, and $\left[\mathrm{N}_{8,8,8,8}\right][\mathrm{BSB}]$ was chosen as the most suitable because of the lowest melting point. A Nernstian response was observed over the range $10^{-4}$ or $10^{-5}$ to $10^{-1} \mathrm{M}$ (see Figure 6) for the four chosen analyte ions, with good reproducibility and reversibility and a fast response time of $<10$ seconds. 
Peng et al. ${ }^{55}$ reported a sulfate ion sensor based on a PVC membrane containing either one of the two RTILs $\left[\mathrm{C}_{8} \mathrm{mim}\right] \mathrm{Cl}$ or $\left[\mathrm{P}_{14,6,6,6}\right] \mathrm{Cl}$ as both an anion exchanger and plasticizer, and sulfate ionophore I (1,3-[Bis(3-phenylthioureidomethyl)]benzene). Both membranes exhibited ideal Nernstian responses to sulfate over the range $10^{-5}$ to $10^{-1} \mathrm{M}$ and were successfully applied for the analysis of sulfate in drinking water samples. The same group ${ }^{56}$ employed a polymer/IL/multiwalled-CNT composite electrode as an all solid-state potentiometric sensor for various anions $\left(\mathrm{SO}_{4}{ }^{2-}, \mathrm{Cl}^{-}, \mathrm{NO}_{3}{ }^{-}, \mathrm{Sal}^{-}, \mathrm{SCN}^{-}\right.$and $\left.\mathrm{ClO}_{4}{ }^{-}\right)$. The ionic liquid $\left[\mathrm{P}_{14,6,6,6}\right] \mathrm{Cl}$ was added to the PVC membrane in the ratio $20 \mathrm{wt} . \%$ IL to $80 \mathrm{wt}$ \% PVC. It was noted that the sensor suffered from severe potential instability due to the tendency of the IL to absorb water, but this was improved by the addition to CNTs to the membrane, resulting in a stable Nernstian response over the concentration range $10^{-5}$ to $10^{-1} \mathrm{M}$.

Faridbod et al. ${ }^{57}$ developed a potentiometric Er(III) sensor consisting of a multi-walled $\mathrm{CNT} /\left[\mathrm{C}_{4} \mathrm{mim}\right]\left[\mathrm{BF}_{4}\right]$ carbon paste electrode containing 5-(dimethylamino)naphthalene-1-sulfonyl-4phenylsemicarbazide (NSP) as the sensing material. A Nernstian response of $19.8 \mathrm{mV}$ per decade was observed in the range $10^{-7}$ to $10^{-1} \mathrm{M}$ with a detection limit of $5 \times 10^{-8} \mathrm{M}$ for $\mathrm{Er}(\mathrm{III})$. Using the RTIL as a binder showed improved performance compared to mineral oil (paraffin), and the combination of the three sensing materials gave better sensitivity, selectivity, response time and stability compared to traditional Er(III) carbon paste sensors.

It is clear from these reports that RTILs have the ability to be used in membranes of ISEs. However, the long-term stability of such sensors may be restricted by the leaching of IL ions from the membrane into the water phase. At present, the ILs available may not be sufficiently lipophilic to serve as suitable replacements for components in conventional ISEs (e.g. ion-exchangers in PVC membranes). Research in this field may be restricted until new highly lipophilic ILs are synthesized.

\subsection{Sensing of Biological Molecules}

RTILs have been shown to be ideal candidates as replacement electrolytes in biosensors due to their intrinsic conductivity, high stability and excellent biocompatibility. A recent review paper by 
Shiddiky and Torriero ${ }^{27}$ describes in detail the recent development and construction of IL based electrochemical biosensing systems, including carbon ionic liquid electrodes (CILEs) and ionic liquid-modified macrodisk electrodes. Since the authors cover the majority of the work in the biosensing area up to 2011, the focus here will be only on the direct detection of biological molecules using RTILs. The ability to detect biological molecules directly without a biomolecular recognition is desirable to obtain important information on their intrinsic thermodynamic and kinetic properties (formal potentials, electron transfer rate constants, diffusion coefficients and coupled chemical reactions), ${ }^{58}$ which may be different in RTILs and conventional solvents. To date, there is relatively little information available on the fundamental behaviour of biological molecules in RTILs; however, this information can provide the basis for the development of sensors employing RTILs either as the solvent medium, or as a droplet (e.g. on a solid electrode) in aqueous media. Below are some recent examples of direct electrochemical detection of biological molecules using RTILs. For more detail on the use of RTILs specifically in biosensors, interested readers are directed to the biosensor-focussed review paper. ${ }^{27}$

Loget et al. ${ }^{31}$ reported the direct electron transfer to hemoglobin $(\mathrm{Hb})$ and myoglobin $(\mathrm{Mb})$ at a glassy carbon electrode in water using an RTIL $\left(\left[\mathrm{C}_{4} \mathrm{mim}\right]\left[\mathrm{BF}_{4}\right]\right)$ as the electrolyte. In this study, $\mathrm{Hb}$ and $\mathrm{Mb}$ were reduced by 4 and 1 electron(s), respectively. Sharp and well-defined voltammograms were observed for $\mathrm{Hb}$ and $\mathrm{Mb}$, indicating that the proteins are not strongly adsorbed on the electrode surface, which is in contrast to most works in traditional electrolyte media. It was observed that the RTIL promoted and facilitated the electron transfer between the electrode and the proteins, possibly due to the bulky RTIL ions that provide a micro-environment suitable for orientation of the heme proteins on the electrode surface. This provides a means to detect $\mathrm{Hb}$ and $\mathrm{Mb}$ at a bare glassy carbon electrode in water/RTIL solutions.

ShangGuan et al. ${ }^{59}$ reported the electrochemical oxidation of paracetamol in water solutions (0.1 $\mathrm{M}$ acetate buffer) using a carbon-RTIL ([ $\left.\left.\mathrm{C}_{4} \mathrm{mim}\right]\left[\mathrm{PF}_{6}\right]\right)$ electrode. Higher currents were observed and the voltammetric behaviour indicates that the reaction is more electrochemically reversible compared to similar electrodes with a traditional oil-based binder. The carbon-RTIL 
electrode showed linearity (current vs. concentration) in the range $1 \times 10^{-6} \mathrm{M}$ to $2 \times 10^{-3} \mathrm{M}$ with a detection limit of $0.3 \mu \mathrm{M}$. The electrode showed good sensitivity and reproducible response even in the presence of interferents (e.g ascorbic acid, caffeine, $p$-aminophenol, glucose and urea) that are commonly found in pharmaceutical and urine samples.

The use of screen printed electrodes with RTILs has also recently become a focus for direct sensing of biological molecules. For example, Chernyshov et al. ${ }^{60}$ used a screen-printed electrode modified with a graphite-RTIL ([C $\left.\left.\mathrm{C}_{4} \mathrm{dmim}\right]\left[\mathrm{NTf}_{2}\right]\right)$ composite for the voltammetric detection of dopamine, adrenaline and dobutamine in aqueous solutions. Calibration graphs were linear for current vs. concentration over the concentration ranges: $4 \times 10^{-6} \mathrm{M}$ to $1 \times 10^{-4} \mathrm{M}$ (for dopamine), $3 \times 10^{-7} \mathrm{M}$ to $1 \times 10^{-4} \mathrm{M}$ (adrenaline) and $2 \times 10^{-7} \mathrm{M}$ to $1 \times 10^{-4} \mathrm{M}$ (dobutamine), with detection limits of $1.2 \mu \mathrm{M}, 1.3 \mu \mathrm{M}$ and $5.3 \mu \mathrm{M}$, respectively. The electrode response was stable and reproducible, although the authors note that relatively water soluble RTILs (such as others that were studied in their work) may not be suitable for the fabrication of long-life sensors due to leakage of RTIL ions into the aqueous phase. A similar problem occurs with membrane ISEs, as discussed in section 2.3. Notable work was performed by Ping et al. ${ }^{61}$ who used a screen-printed electrode bulk-modified with graphite, cellulose, acetate and the ionic liquid $\left[\mathrm{C}_{8} \mathrm{Py}\right]\left[\mathrm{PF}_{6}\right]$ for the detection of dopamine in aqueous solutions. A linear range (current vs. concentration) of $1 \times 10^{-6} \mathrm{M}$ to $2.5 \times 10^{-3} \mathrm{M}$ and detection limit of $0.5 \mu \mathrm{M}$ was reported for dopamine at the modified electrode.

Compton's group have been active in this area and have employed RTILs in modified electrodes or used them directly as solvents for the detection of various biological molecules. For example they employed a carbon nanotube-ionic liquid ([C $\left.\left.{ }_{8} \mathrm{Py}\right]\left[\mathrm{PF}_{6}\right]\right)$ composite sensor for the detection of ascorbic acid, hydrogen peroxide and nicotinamide adenine dinucleotide (NADH). ${ }^{62}$ The sensor showed low background current, high sensitivity, high stability and good reproducibility. They followed this with a study of the direct electrochemistry of NADH in two RTILs, $\left[\mathrm{C}_{2} \mathrm{mim}\right]\left[\mathrm{NTf}_{2}\right]$ and $\left[\mathrm{C}_{4} \mathrm{mim}\right]\left[\mathrm{PF}_{6}\right]^{63}$ on a platinum electrode. Voltammetric peaks for $\mathrm{NADH}$ were observed in $\left[\mathrm{C}_{4} \mathrm{mim}\right]\left[\mathrm{PF}_{6}\right]$ but not in $\left[\mathrm{C}_{2} \mathrm{mim}\right]\left[\mathrm{NTf}_{2}\right]$, suggesting that careful choice of 
the RTIL nature is extremely important. This knowledge is highly beneficial for researchers choosing the most appropriate RTIL to employ for selective analyte sensing. Compton's group also reported the electrochemical reduction of guanine and adenine on Pt in a wide range of RTILs: $\left[\mathrm{N}_{6,2,2,2}\right]\left[\mathrm{NTf}_{2}\right], \quad\left[\mathrm{C}_{4} \mathrm{mim}\right]\left[\mathrm{PF}_{6}\right], \quad\left[\mathrm{C}_{4} \mathrm{mpyrr}\right]\left[\mathrm{NTf}_{2}\right], \quad\left[\mathrm{C}_{4} \mathrm{mim}\right]\left[\mathrm{NTf}_{2}\right], \quad\left[\mathrm{C}_{4} \mathrm{mpyrr}\right]\left[\mathrm{N}(\mathrm{CN})_{2}\right]$ and $\left[\mathrm{P}_{14,6,6,6}\right][\mathrm{FAP}] .{ }^{64}$ In two of the ionic liquids $\left(\left[\mathrm{N}_{6,2,2,2}\right]\left[\mathrm{NTf}_{2}\right]\right.$ and $\left.\left[\mathrm{P}_{14,6,6,6}\right][\mathrm{FAP}]\right)$ a one-electron reduction of both guanine and adenine is observed, followed by a chemical step (e.g. dimerization). These analytes can be monitored in the concentration range from 2 to $30 \mathrm{mM}$ in RTILs, suggesting a suitable method for their detection. The voltammetry of catechol and dopamine was also reported on bare Pt electrodes in the RTILs $\left[\mathrm{C}_{2} \mathrm{mim}\right]\left[\mathrm{NTf}_{2}\right]$ and $\left[\mathrm{C}_{4} \mathrm{mim}\right]\left[\mathrm{BF}_{4}\right]$ by the same group, ${ }^{65}$ suggesting the possibility for the detection of these biologically important molecules.

A sensor for the simultaneous voltammetric detection of guanine and adenine was proposed by Xiao et al. ${ }^{66}$ The electrode was prepared using multi walled carbon nanotubes (MWCNTs) with the RTIL $\left[\mathrm{C}_{4} \mathrm{mim}\right]\left[\mathrm{PF}_{6}\right]$ as a binder, followed by electrodeposition of gold nanoparticles from a $\mathrm{HAuCl}_{4}$ solution onto the carbon-paste electrode. Anodic stripping voltammetry was observed for guanine and adenine at different potentials, and the peak potentials were sufficiently separated for simultaneous detection. Peak currents for both analytes were linearly proportional to concentration in the range $9 \times 10^{-7} \mathrm{M}$ to $1.4 \times 10^{-4} \mathrm{M}$ and detection limits down to nanomolar levels were achieved after an accumulation step of 150 seconds. The sensitivities were unchanged when the other species was present in the same sample. This sensor was applied for the detection of guanine and adenine in real-world samples (milk, plasma and urine).

As can be deduced from these reports, the ability to detect and monitor the concentrations of biological molecules is extremely important, particularly in medical and environmental samples (e.g. blood/urine/water). Understanding the behaviour of biological molecules in RTILs is an important step towards developing commercial sensors containing RTILs, whether they be with ('biosensor') or without a bio-recognition process, and more fundamental research is required in this important area. 


\subsection{Detection of Explosives and Chemical Warfare Agents}

Although many of the new developments in this area can be covered by one of the previous headings (e.g. sensing at solid electrodes or gas sensing), it seemed appropriate to give this topic a separate section to highlight the importance of this area. With the increasing need for sensors for explosive materials at airports and security installations (which may be at risk from improvised explosive devices) the interest in developing electrochemical sensors for the detection of explosives is growing rapidly, and in the past few years, there have been several reports on the detection of explosive and toxic materials (e.g. chemical warfare agents, CWAs) using RTILs as a solvent/supporting electrolyte. RTILs are conductive and have low-volatility, allowing them to be deployed in many types of extreme environments (e.g. hot/dry/arid conditions) where other sensor electrolytes would fail. This section describes some of the most interesting work in explosives/CWA detection using RTILs since 2008.

An ionic liquid thin layer electrochemical quartz crystal microbalance (EQCM) sensor to detect nitro aromatic compounds such as ethyl nitrobenzene and dinitrotoluene (both analogues of redox active explosives) was reported by Yu et al. ${ }^{67}$ The sensor combined both electrochemical and piezoelectric transduction mechanisms into a minituarized platform with a counter, working and reference electrode. The combination of two methods can be used to cross-validate the measurement and increase the accuracy of detection. The RTIL $\left[\mathrm{C}_{4} \mathrm{mim}\right]\left[\mathrm{BF}_{4}\right]$ had a dual function: as a liquid medium to connect all three electrodes (for amperometry) and as a medium for the preconcentration of explosive vapours (for amperometry and QCM).

Forzani et al. ${ }^{68}$ proposed a hybrid electrochemical-colorimetric sensing platform for the detection of explosive trinitrotoluene (TNT) vapours as shown in Figure 7. A thin layer of the RTIL $\left[\mathrm{C}_{4} \mathrm{mim}\right]\left[\mathrm{PF}_{6}\right]$ was found to selectively pre-concentrate the explosive materials and quickly transport the analytes to the electrodes. The explosive vapours were detected by electrochemical (cyclic voltammetry) and colorimetric (absorbance change) methods at the working electrode. The observed currents and distinct colour changes provide a fingerprint for the identification and quantification of TNT. The same group ${ }^{69}$ later employed a conducting polymer nanojunction that 
was sensitive only to the reduction products of TNT and was able to discriminate from other redoxactive interferents found in ambient air. The sensor simultaneously measured the current for the reduction of TNT and the resulting conductance change of the polymer (poly(ethylenedioxythiophene), PEDOT). A linear response (current vs. concentration) was observed at concentrations of $30 \mathrm{pM}$ to $6 \mathrm{nM}$ TNT (when present in the liquid phase) and the sensor was capable of detecting extremely low levels of TNT (ppt) within 1-2 minutes.

Graphene, in conjunction with RTILs, has also been employed for highly selective sensing of explosive TNT by Guo et al. ${ }^{70}$ The RTIL $\left[\mathrm{C}_{4} \mathrm{mim}\right]\left[\mathrm{PF}_{6}\right]$ was combined with three-dimensional graphene to make an ionic liquid-graphene paste electrode with a large surface area, low background current and pronounced mesoporosity. A linear relationship was observed between peak current (using absorptive stripping voltammetry) and concentration from 2 to $1000 \mathrm{ppb}$, with a low detection limit of $0.5 \mathrm{ppb}$ for TNT. This was superior to that demonstrated by RTIL-CNT and RTIL-graphite composites.

Jayawardhana et al. ${ }^{71}$ reported a rapid and sensitive stochastic nanopore sensing method for the detection of monovalent cations and liquid explosive components and their sensitizers. They employed a $\alpha$-hemolysin protein pore with botomycin (molecular adaptor) as the sensing element and the RTIL $\left[\mathrm{C}_{4} \mathrm{mim}\right] \mathrm{Cl}$ as a background electrolyte (1 $\mathrm{M}$ in water). This pioneering work is believed to be the first time that RTILs have been successfully introduced as supporting electrolytes in nanopore technology, and permits the analysis of compounds that are difficult or even impossible to detect in aqueous solutions due to their limited solubility.

Singh et al. ${ }^{72}$ reported the electrochemical detection for the chemical warfare agent (CWA) nitrogen mustard-2 (NM-2) on platinum in the RTIL $\left[\mathrm{S}_{2,2,2}\right]\left[\mathrm{NTf}_{2}\right]$. A one-electron oxidation peak was observed on the anodic sweep and a reduction wave was observed on the cathodic sweep. This is believed to be the first report of cyclic voltammetry for any CWA in ionic liquids. A diffusion coefficient of $1.8 \times 10^{-10} \mathrm{~m}^{2} \mathrm{~s}^{-1}$ for NM-2 was calculated, which is the same order of magnitude for other gases (e.g. $\mathrm{O}_{2}, \mathrm{H}_{2}$ ) in RTILs. ${ }^{43}$ A linear relationship was observed between current (reduction) and concentration in the range $29 \mu \mathrm{M}$ and $1.2 \mathrm{mM}$, with a detection limit of $15 \mu \mathrm{M}$. The levels at 
which this gas is toxic is much lower, but this study provides a basis for its detection and room for improvement. The authors suggest that RTILs are an alternative greener medium for the detection of toxic CWAs and this suggests that more work is needed in this important area.

These interesting works have shown that it is possible to selectively detect highly dangerous explosive and toxic species using an RTIL as an electrolyte and/or pre-concentration medium. In may cases, the RTIL has been combined with other materials (e.g. nanomaterials), or the electrochemical technique has been combined with a complementary technique. It seems that the high viscosity of RTILs compared to conventional solvent/electrolyte systems (resulting in slower mass transport, smaller diffusion coefficients and therefore lower currents) may prevent the detection of trace quantities of explosives that are required for a viable real-world sensor. However, perhaps one of their most useful applications could be as electrolytes in sensors that can be deployed directly after an explosion in an enclosed area where temperature could still be high and other electrolytes would volatilize. This would allow for the fast identification of "hot", "warm” and “cold” zones, allowing forensic personnel to determine areas that are safe to enter for postexplosion analysis.

\section{Conclusions and Future Prospectives}

This article has described the recent developments (over the last 3 years) in the use of ionic liquids for electrochemical sensing applications. Their use in voltammetric sensing at solid/liquid and liquid/liquid interfaces, use as a binder in carbon paste electrodes, in gas sensing, ISEs, and for detecting biological molecules, explosives and CWAs has been discussed. The large amount of interest in applying ILs in electrochemical sensors is likely due to the highly robust and non-volatile (“green”) nature of ionic liquids, which means they can be applied in a range of harsh environments without the issues of solvent evaporation that occurs with conventional solvents. Some possible future directions for each type of sensing technique/area have been discussed throughout this article and include the wider implementation of TSILs for tuning reactivity in voltammetric sensing, the requirement for extremely hydrophobic RTILs to: (1) extend the available potential windows for 
sensing at liquid/liquid interfaces and (2) be used in ISEs without the issue of leakage into the aqueous phase. For gas sensors, the expected future direction is in the use of very thin layers (to provide faster response times) and using very small (e.g. micron-sized) working electrodes (for higher current densities and reduced iR drop). For electrochemical explosives sensing, it appears that RTILs have to be combined with either (1) nanomaterials or (2) complementary techniques, since electrochemical sensing in RTILs alone does not seem to be sensitive enough to detect the low/trace concentrations required. However, some significant discoveries in this field are expected due to the increasing need for portable explosive sensors in a wide range of environments. RTILs have shown the most amount of promise when used as a binder in conjunction with carbon nanomaterials due to the ease of preparation, higher currents (compared to oil-CPEs), high sensitivity, good reproducibility, low cost and long-term stability. As a result, there is much more work expected in this area in the near future.

Based on the work reviewed here, it appears that there are currently a number of challenges associated with employing RTILs as replacement electrolytes in electrochemical sensors. Firstly, any practical implementation of a sensor (particularly amperometric) requires careful control of the potential vs. a stable reference electrode. This is an ongoing problem that is still yet to be answered in ionic liquids ${ }^{73}$ and more work is needed on this topic; there has been a full discussion on this topic in a book chapter by Silvester et $a .^{74}$ Another issue is the intrinsic impurities present in RTILs, such as unreacted starting material (e.g. chloride), water and dissolved gases (e.g. oxygen), all of which can interfere with the electrochemical response of the analyte. However, most RTILs that are now commercially available contain many fewer impurities than when they were first available, since there is now a better understanding of the synthetic methods to produce RTILs on a bulk scale, resulting in impurity levels that are very low. Humidity monitors may also need to be employed to account for the varying water contents in the RTILs in a range of real environments, which have been shown to affect the viscosity and the electrochemical response. ${ }^{23}$ The third issue is the high viscosity of RTILs, which may prove be a particular challenge in voltammetric and gas sensing, giving slower current responses and poorer detection limits compared to conventional 
solvent/electrolyte systems. The slow response time can be overcome by using thinner RTIL layers and the poorer detection limits may mean that RTILs may only be useful for higher (ppm to \%) concentrations of gases as opposed to trace (ppb) levels. However, due to their very low volatility RTIL-based gas sensors have the ability to be used in environments currently unavailable to conventional sensor devices where gas detection is required (e.g. "downhole” in the oil and gas industry and in high temperature environments such as mining sites and post-explosion sites). The other main challenge associated with RTIL-based sensors is the selectivity towards one particular analyte species in the presence of a complex mixture. However, this is a challenge common to all conventional sensing devices, not just those containing RTILs.

Despite these challenges, clearly the tuneability of RTILs and their ability to be easily combined with other materials makes them ideal candidates as electrolytes in a range of electrochemical devices. Although this field is still in the development stage, it is envisioned that in the next decade we will see some significant advances towards commercialization of RTIL-based electrochemical sensing systems, particularly when using RTILs as a binder and in the field of amperometric gas sensing.

\section{Acknowledgements}

D.S.S. thanks Curtin University for a Curtin Research Fellowship and D.W.M. Arrigan for useful discussions and suggestions. 


\section{Figure legends}

Figure 1. Names, abbreviations and chemical structures of the ionic liquid cations and anions described in this article.

Figure 2. Top: Schematic diagram of an electrochemical sensor with a thin layer of task specific ionic liquid (TSIL) as a selective solubilization medium. Bottom: square wave voltammetric response of $8 \mathrm{ng} / \mathrm{L} \mathrm{PbO}, \mathrm{CdO}$ and $\mathrm{CuO}$ in the absence (black line) and presence (red line) of $10 \mathrm{ng} / \mathrm{L} \mathrm{Bi}_{2} \mathrm{O}_{3} \cdot{ }^{29}$ Copyright Elsevier. Reproduced with permission.

Figure 3. Comparison of the mechanism of electrode reaction of a polar reactant at a traditional oil-based carbon paste electrode and IL-carbon paste electrode. Arched arrows indicate heterogeneous electron transfer, whereas straight arrows indicate transfer across the liquid/liquid interface. ${ }^{33}$ Copyright Elsevier. Reproduced with permission.

Figure 4. Schematic diagrams of various gas sensing devices. ${ }^{43}$ Copyright The Electrochemical Society. Reproduced with permission.

Figure 5. (a) Schematic illustration of the ethylene sensing mechanism. Ethylene dissolves in a thin ionic-liquid layer covering a gold working electrode. If a sufficiently high potential $E$ is applied to the working electrode, the ethylene is oxidized, resulting in a faradaic current i. (b) Photograph of a sensor, consisting of a Au disk working electrode (WE), surrounded by a Pt ring-shaped quasi-reference electrode (REF) and Pt rectangular counter electrode (CE). (c) Photograph of a DIL package containing two chips and a total of four devices that were wire-bonded and covered by epoxy. Reprinted with permission from Zevenbergen et al. ${ }^{50}$ Copyright 2011, American Chemical Society.

Figure 6. Potentiometric response of a bulk $\left[\mathrm{N}_{8,8,8,8}\right][\mathrm{BSB}]$-based solid membrane electrode towards different anions (triangle=salicylate; diamond=perchlorate; 
circle=thiocyanate; square=iodide) ${ }^{54}$ Copyright American Chemical Society. Reproduced with permission.

Figure 7. Hybrid electrochemical-colorimetric sensor with a thin layer of ionic liquid as a selective preconcentration medium. (A) Cyclic voltammograms of blank IL $\left[\mathrm{C}_{4} \mathrm{mim}\right]\left[\mathrm{PF}_{6}\right]$ (black line) and $2 \mathrm{ppm}$ TNT in the IL (red line) at $100 \mathrm{mVs}^{-1}$. Arrows indicate peak currents of TNT. (B) Colour (absorbance) changes during the electrochemical reduction of $\mathrm{TNT}$ in $\left[\mathrm{C}_{4} \mathrm{mim}\right]\left[\mathrm{PF}_{6}\right]$. Inset to part $\mathrm{B}$ shows two images taken before $(0.0 \mathrm{~V})$ and after $(-1.5 \mathrm{~V})$ TNT reduction. The distinct colour change provides a fingerprint for identification and quantification of the explosive. ${ }^{6}$ Copyright American Chemical Society. Reproduced with permission. 
Figure 1.<smiles>CCCCCCCCCCCCn1cc[n+](C)c1</smiles>

1-alkyl-3-methylimidazolium, $\left[\mathrm{C}_{n} \mathrm{mim}\right]^{+}$<smiles>CCC[N+]1(C)CCCC1</smiles>

Pyrrolidinium, $\left[\mathrm{C}_{n} \mathrm{mpyrr}\right]^{+}$<smiles>CCCCCCCCCCCCCCCCCCC</smiles>

1-alkyl-2,3-dimethylimidazolium, $\left[\mathrm{C}_{n} \mathrm{dmim}\right]^{+}$<smiles>O=S(=O)(NS(=O)(=O)C(F)(F)F)C(F)(F)F</smiles>

Bis(trifluoromethylsulfonyl)imide, $\left[\mathrm{NTf}_{2}\right]^{-}$

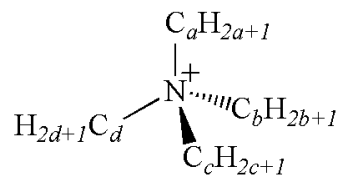

Tetraalkylammonium, $\left[\mathrm{N}_{a, b, c, d}\right]^{+}$<smiles>CCCCCCCC</smiles>

Pyridinium, $\left[\mathrm{C}_{n} \mathrm{Py}\right]^{+}$<smiles>CC1(C)C2CCC[C@]1(CS(=O)(=O)[O-])C(=O)C2</smiles>

Camphorsulfonate, $[\mathrm{CS}]^{-}$<smiles>F[B-](F)(F)I</smiles>

Tetrafluoroborate $\left[\mathrm{BF}_{4}\right]^{-}$<smiles>CC(=O)[O-]</smiles>

Acetate $[\mathrm{Ac}]^{-}$

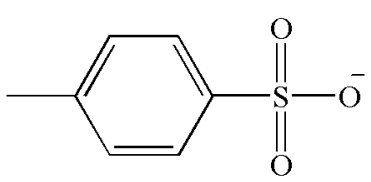

Tosylate [Ts]

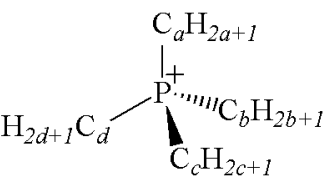

Tetraalkylphosphonium, $\left[\mathrm{P}_{a, b, c, d}\right]^{+}$<smiles>CCCCCCC</smiles>

Trialkylsulfonium, $\left[\mathrm{S}_{a, b, c}\right]^{+}$<smiles>O=C1O[B-]2(OC(=O)c3ccccc3O2)Oc2ccccc21</smiles>

Bis[salicylato(2-)]borate, [BSB]

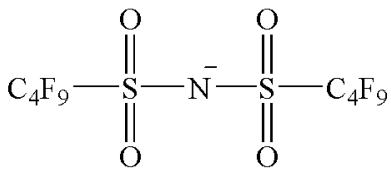<smiles>FC(F)(F)P(F)(F)(F)(F)(F)C(F)(F)F</smiles>

Trifluorotris(pentafluoroethyl)phosphate, $\left.{ }^{[\mathrm{FAP}}\right]^{-}$<smiles>Fc1c(F)c(F)c(CP)c(F)c1F</smiles>

Tetrakis(pentafluorophenyl)borate, [TPBF20]<smiles></smiles>

Trifluoromethylsulfonate, [OTf $]^{-}$<smiles>CCOS(=O)(=O)[O-]</smiles>

Ethyl sulphate $\left[\mathrm{EtSO}_{4}\right]^{-}$<smiles>N#C[N-]C#N</smiles>

Dicyanamide $\left[\mathrm{N}(\mathrm{CN})_{2}\right]$<smiles>[B]c1cc(C)cc(C(F)(F)F)c1</smiles>

Tetrakis[3,5-bis(trifluoromethyl) phenyl]borate, [TFPB]<smiles>FP(F)(F)(F)(F)(F)F</smiles>

Hexafluorophosphate, $\left[\mathrm{PF}_{6}\right]^{-}$ 
Figure 2.

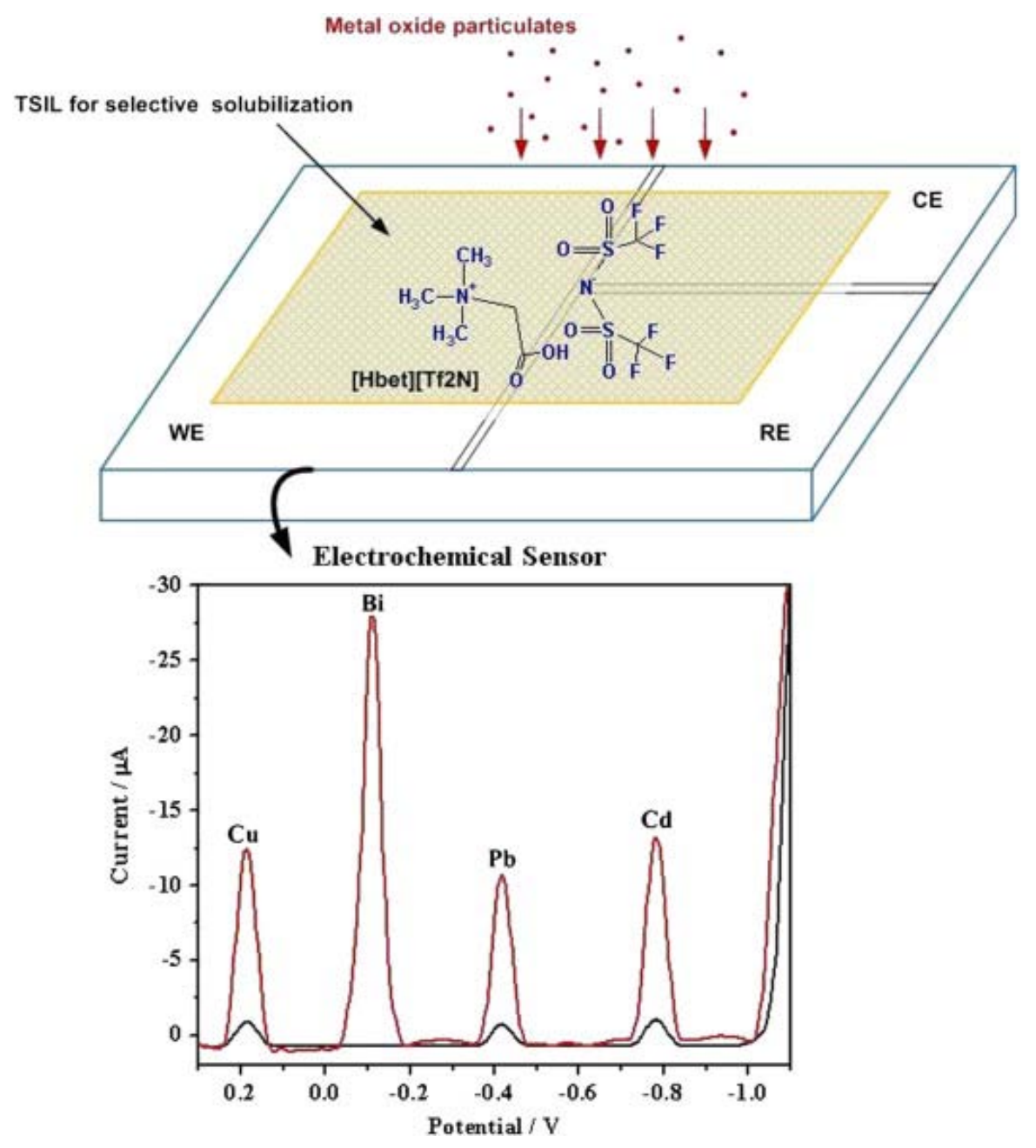

Figure 3.
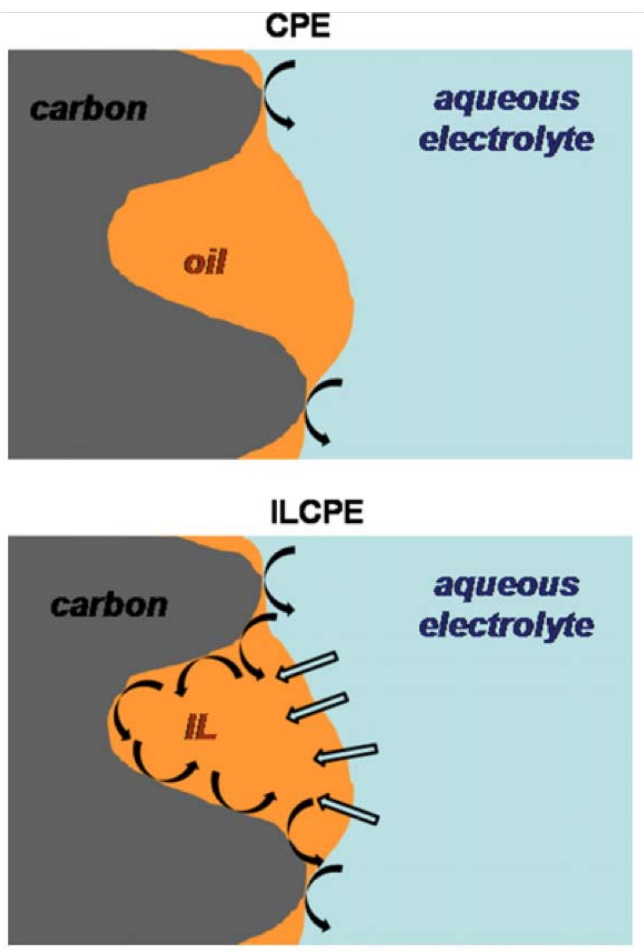
Figure 4.

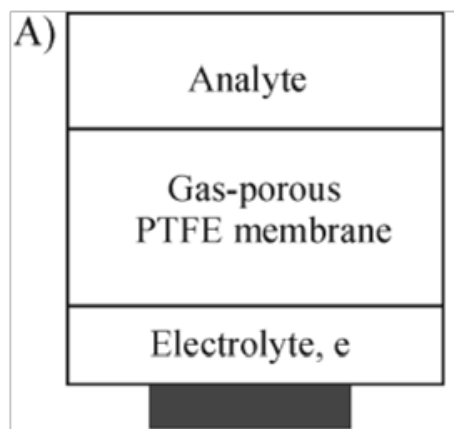

Macroelectrode

$\left(\mathrm{r}_{\mathrm{e}}=500 \mu \mathrm{m}\right)$

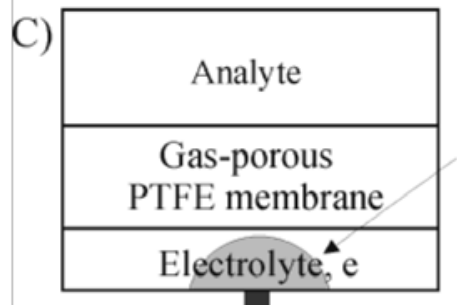

Microelectrode

$\left(\mathrm{r}_{\mathrm{e}}=2 \mu \mathrm{m}\right)$
B)

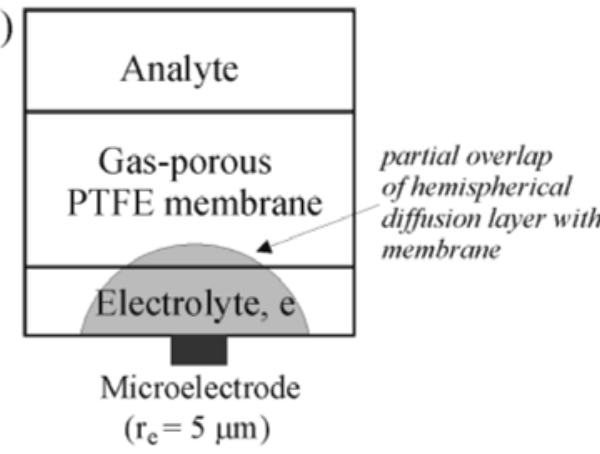

D)

no overlap of

hemispherical

diffusion layer

with membrane

\begin{tabular}{|c|}
\hline Analyte \\
\hline Electrolyte, $\mathrm{e}$ \\
\hline
\end{tabular}

Microelectrode

$\left(\mathrm{r}_{\mathrm{e}}=2 \mu \mathrm{m}\right)$ 
Figure 5.

(a)

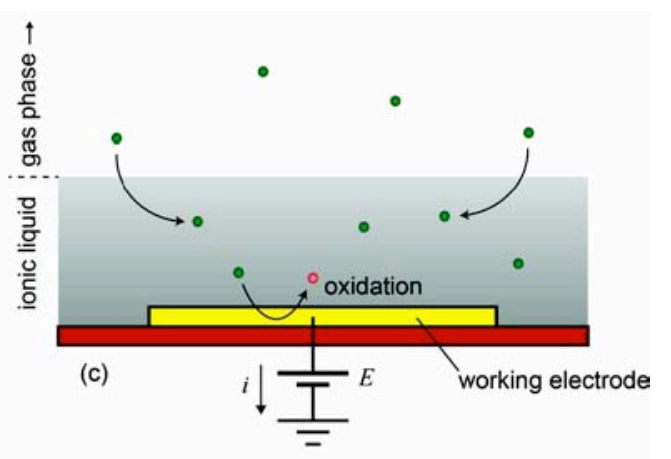

(b)

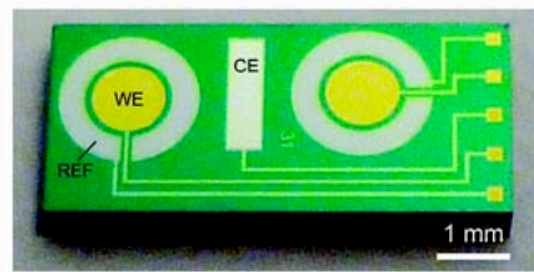

(c)

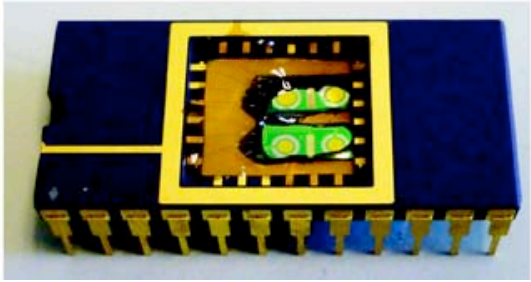

Figure 6.

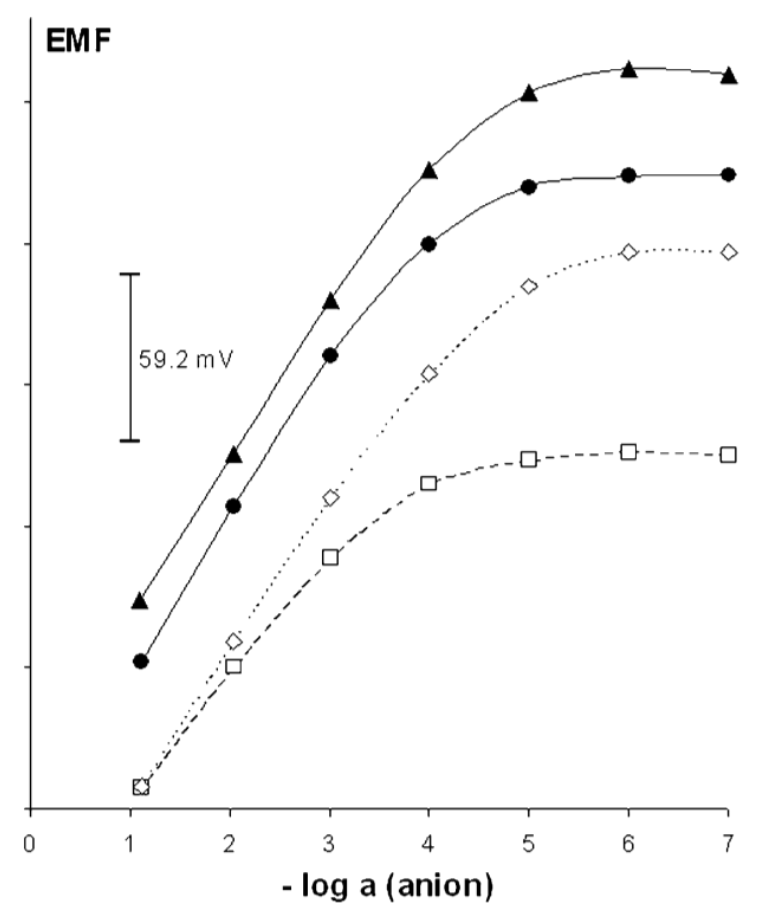


Figure 7.

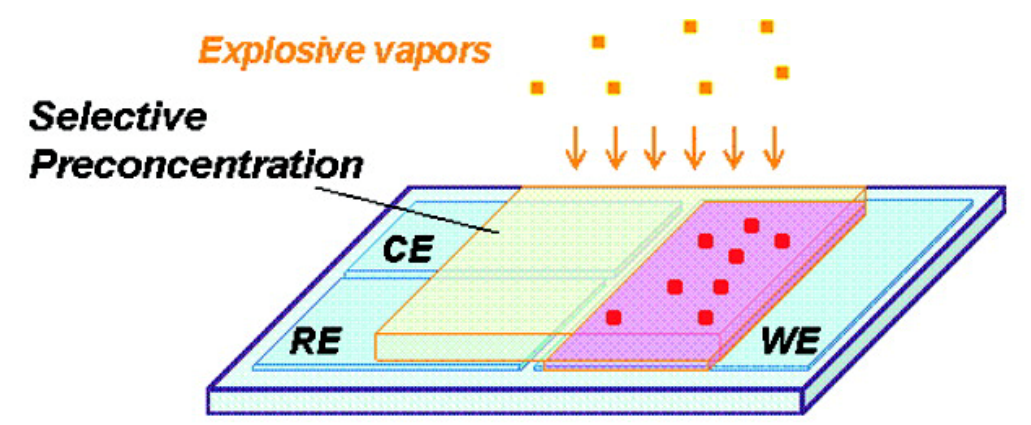

Hybrid Electrochemical Colorimetric Sensor

After reduction
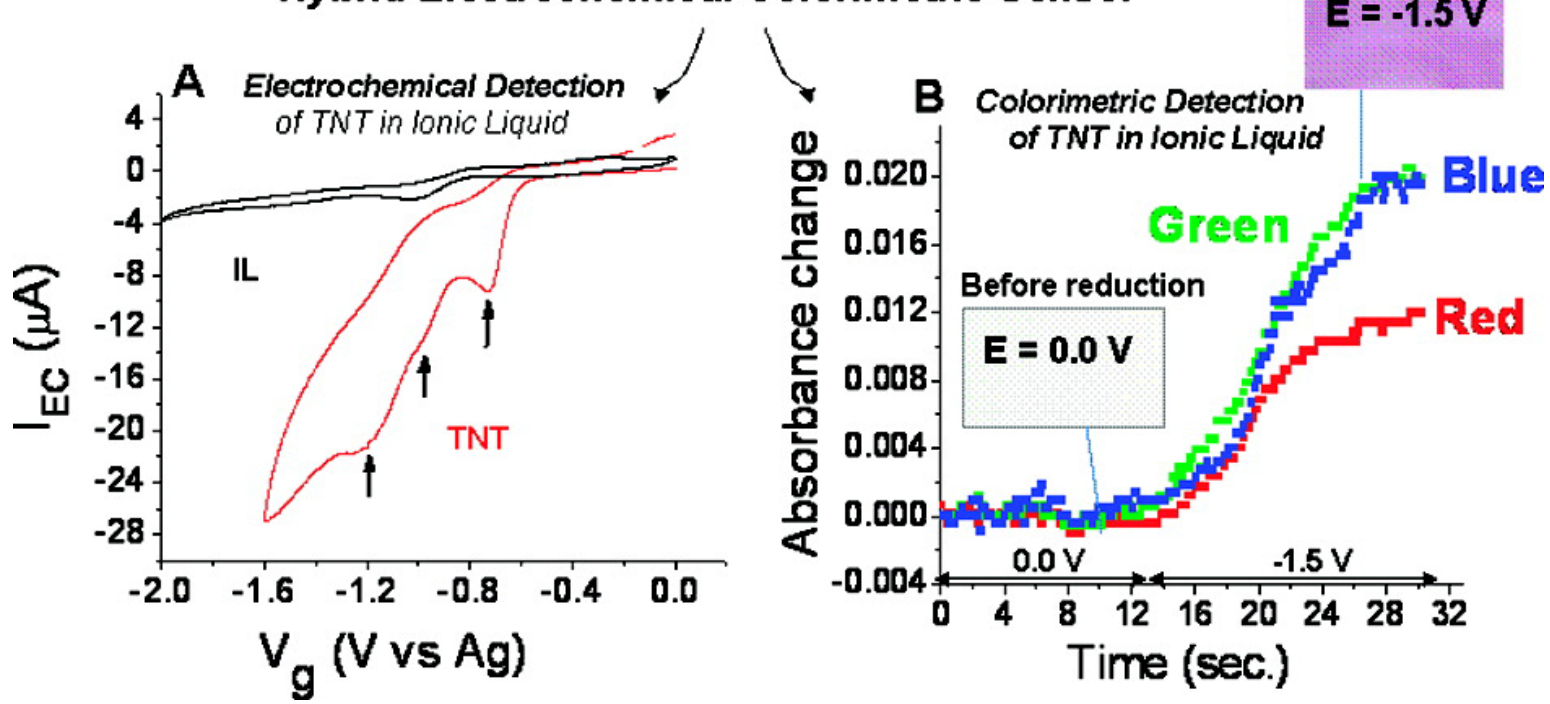


\section{References:}

1. T. Welton, Chem. Rev., 1999, 99, 2071-2083.

2. $\quad$ P. Wasserscheid and W. Keim, Angew. Chem. Int. Ed., 2000, 39, 3772-3789.

3. J. S. Wilkes, J. Mol. Catalysis A, 2004, 214, 11-17.

4. J. Dupont, C. S. Consortia and J. Spencer, J. Braz. Chem. Soc., 2000, 11, 337-344.

5. M. J. Earle and K. R. Seddon, Pure Appl. Chem., 2000, 72, 1391-1398.

6. C. Chiappe and D. Pieraccini, J. Phys. Org. Chem., 2005, 18, 275-297.

7. S. Chowdhury, R. S. Mohan and J. L. Scott, Tetrahedron, 2007, 63, 2363-2389.

8. G. A. Baker, S. N. Baker, S. Pandey and F. V. Bright, Analyst, 2005, 130, 800-808.

9. $\quad$ S. Pandey, Anal. Chim. Acta, 2006, 556, 38-45.

10. R. A. Sheldon, M. L. R., M. J. Sorgedrager, F. van Rantwijk and K. R. Seddon, Green. Chem., 2002, 4, 147-151.

11. F. van Rantwijk and R. A. Sheldon, Chem. Rev., 2007, 107, 2757-2785.

12. N. V. Plechkova and K. R. Seddon, Chem. Soc. Rev., 2008, 37, 123-150.

13. W. Lu, I. D. Norris and B. R. Mattes, Aust. J. Chem., 2005, 58, 263-269.

14. A. Lewandowski and M. Galinski, J. Phys. Chem. Solids, 2004, 65, 281-286.

15. A. B. McEwen, S. F. McDevitt and V. R. Koch, J. Electrochem. Soc., 1997, 144, L84-L86.

16. M. Ue, M. Takeda, A. Toriumi, A. Kominato, R. Hagiwara and Y. Ito, J. Electrochem. Soc., 2003, 150, A499-A502.

17. Y. Wang, K. Zaghib, A. Guerfi, F. F. C. Bazito, R. M. Torresi and J. R. Dahna, Electrochim. Acta, 2007, 52, 6346-6352.

18. R. F. de Souza, J. C. Padilha, R. S. Gonc alves and J. Dupont, Electrochem. Commun., 2003, 5, 728-731.

19. P. Wang, S. M. Zakeeruddin, J.-E. Moser and M. Gratzel, J. Phys. Chem. B, 2003, 107, 13280-13285.

20. M. C. Buzzeo, C. Hardacre and R. G. Compton, Anal. Chem., 2004, 76, 4583-4588.

21. L. E. Barrosse-Antle, A. M. Bond, R. G. Compton, A. M. O'Mahony, E. I. Rogers and D. S. Silvester, Chem. Asian J., 2010, 5, 202-230.

22. F. Endres and S. Zein El Abedin, Phys. Chem. Chem. Phys., 2006, 8, 2101-2116.

23. D. S. Silvester and R. G. Compton, Z. Phys. Chem., 2006, 220, 1247-1274.

24. P. Hapiot and C. Lagrost, Chem. Rev., 2008, 108, 2238-2264.

25. W. Wei and A. Ivaska, Anal. Chim. Acta, 2008, 607, 126-135.

26. N. V. Shvedene, D. V. Chernyshov and I. V. Pletnev, Russ. J. General Chem., 2008, 52, 8091.

27. M. J. A. Shiddiky and A. A. J. Torriero, Biosens. Bioelectron., 2011, 26, 1775-1787.

28. M. C. Buzzeo, R. G. Evans and R. G. Compton, Phys. Chem. Chem. Phys., 2004, 5, 11061120.

29. D. Lu, N. Shomali and A. Shen, Electrochem. Commun., 2010, 12, 1214-1217.

30. J.-F. Huang and B.-T. Lin, Analyst, 2009, 134, 2306-2313.

31. Z. Samec, Pure Appl. Chem., 2004, 76, 2147-2180.

32. Z. Samec, J. Langmaier and T. Kakiuchi, Pure Appl. Chem., 2009, 81, 1472-1488.

33. M. Opallo and A. Lesniewski, J. Electroanal. Chem., 2011.

34. T. Kakiuchi and N. Tsujioka, Electrochem. Commun., 2003, 5, 253-256.

35. Y. Wang, T. Kakiuchi, Y. Yasui and M. V. Mirkin, J. Am. Chem. Soc., 2010, 132, 1694516952.

36. Y. Yasui, Y. Kitazumi, R. Ishimatsu, N. Nishi and T. Kakiuchi, J. Phys. Chem. B, 2009, 113, 3273-3276.

37. A. D. Ballantyne, A. K. Brisdon and R. A. W. Dryfe, Chem. Commun., 2008, 4980-4982.

38. D. S. Silvester and D. W. M. Arrigan, Electrochem. Commun., 2011, 13, 477-479.

39. G. Herzog, V. Kam and D. W. M. Arrigan, Electrochim. Acta, 2008, 53, 7204-7209.

40. K.-I. Kim, H.-Y. Kang, J.-C. Lee and S.-H. Choi, Sensors, 2009, 9, 6701-6714.

41. X. Sun, S. Hu, L. Li, J. Xiang and W. Sun, J. Electroanal. Chem., 2011, 651, 94-99. 
42. N. Xu, Y. Ding, H. Ai and J. Fei, Microchim. Acta, 2010, 170, 165-170.

43. E. I. Rogers, A. M. O'Mahony, L. Aldous and R. G. Compton, ECS Transactions, 2010, 33, 473-502.

44. X.-J. Huang, L. Aldous, A. O. O’Mahony, F. J. del Campo and R. G. Compton, Anal. Chem., 2010, 82, 5238-5245.

45. L. E. Barrosse-Antle and R. G. Compton, Chem. Commun., 2009, 3744-3746.

46. A. M. O'Mahony and R. G. Compton, Electroanalysis, 2010, 22, 2313 - 2322.

47. X.-J. Huang, D. S. Silvester, I. Streeter, L. Aldous, C. Hardacre and R. G. Compton, J. Phys. Chem. C, 2008, 112, 19477-19483.

48. X. Shen, X. Chen, J.-H. Liu and X.-J. Huang, J. Mater. Chem., 2009, 19, 7687-7693.

49. $\quad$ S. R. Ng, C. X. Guo and C. M. Li, Electroanalysis, 2011, 23, $442-448$.

50. M. A. G. Zevenbergen, D. Wouters, V.-A. T. Dam, S. H. Brongersma and M. CregoCalama, Anal. Chem., 2011, 83, 6300-6307.

51. N. Nishi, H. Murakami, Y. Yasui and T. Kakiuchi, Anal. Sci., 2008, 24, 1315-1320.

52. J. Langmaier and Z. Samec, Anal. Chem., 2009, 81, 6382-6389.

53. J. Langmaier, J. Trojanek and Z. Samec, Electroanalysis, 2009, 21, 1977-1983.

54. D. V. Chernyshov, V. M. Egorov, N. V. Shvedene and I. V. Pletnev, App. Mater. Interfaces, 2009, 1, 2055-2059.

55. B. Peng, J. Zhu, X. Liu and Y. Qin, Sens. Act. B, 2008, 133, 308-314.

56. J. Zhu, Y. Qin and Y. Zhang, Electrochem. Commun., 2009, 11, 1684-1687.

57. F. Faridbod, M. R. Ganjali, B. Larijani and P. Norouzi, Electrochim. Acta, 2009, 55, 234239.

58. F. A. Armstrong, H. A. O. Hill and N. J. Walton, Acc. Chem. Res., 1988, 21, 407-413.

59. X. ShangGuan, H. Zhang and J. Zheng, Anal. Bioanal. Chem., 2008, 391, 1049-1055.

60. D. V. Chernyshov, N. V. Shvedene, E. R. Antipova and I. V. Pletnev, Anal. Chim. Acta, 2008, 621, 178-184.

61. J. Ping, J. Wu and Y. Ying, Electrochem. Commun., 2010, 12, 1738-1741.

62. R. T. Kachoosangi, M. M. Musameh, I. Abu-Yousef, J. M. Yousef, S. M. Kanan, L. Xiao, S. G. Davies, A. Russell and R. G. Compton, Anal. Chem., 2009, 81, 435-442.

63. A. M. O'Mahony, C. Hardacre and R. G. Compton, J. Electrochem. Soc., 2010, 147, F49F53.

64. M. V. B. Zanoni, E. I. Rogers, C. Hardacre and R. G. Compton, Anal. Chim. Acta, 2010, 659, 115-121.

65. E. O. Barnes, A. M. O'Mahony, L. Aldous, C. Hardacre and R. G. Compton, J. Electroanal. Chem., 2010, 646, 11-17.

66. F. Xiao, F. Zhao, J. Li, L. Liu and B. Zeng, Electrochim. Acta, 2008, 53, 7781-7788.

67. L. Yu, Y. Huang, X. Jin, A. J. Mason and X. Zeng, Sens. Act. B, 2009, 140, 363-370.

68. E. S. Forzani, D. Lu, M. J. Leright, A. D. Aguilar, F. Tsow, R. A. Iglesias, Q. Zhang, J. Lu, J. Li and N. Tao, J. Am. Chem. Soc., 2009, 131, 1390-1391.

69. A. D. Aguilar, E. S. Forzani, M. J. Leright, F. Tsow, A. Cagan, R. A. Iglesias, L. A. Nagahara, I. Amlani, R. Tsui and N. J. Tao, Nano Lett., 2010, 10, 380-384.

70. C. X. Guo, Z. S. Lu, Y. Lei and C. M. Li, Electrochem. Commun., 2010, 12, 1237-1240.

71. D. A. Jayawardhana, J. A. Crank, Q. Zhao, D. W. Armstrong and X. Guan, Anal. Chem., 2009, 81, 460-464.

72. V. V. Singh, M. Boopathi, K. Ganesan, B. Singh and R. Vijayaraghavan, Electroanalysis, 2010, 22, 1357-1363.

73. E. I. Rogers, D. S. Silvester, D. L. Poole, L. Aldous, C. Hardacre and R. G. Compton, J. Phys. Chem. C, 2008, 112, 2729-2735.

74. D. S. Silvester, E. I. Rogers and R. G. Compton, Chapter 13.2: Reference Electrodes for use in RTILs in Electrodeposition from Ionic Liquids, eds. F. Endres, D. R. MacFarlane and A. Abbot, Wiley, Weinheim Germany, 2008. 